\title{
VALOR NUTRITIVO DE PE DE MILHO SECO (ZEA MAYS) DETERMINADO NUM ENSAIO DE DIGESTIBILIDADE COM BOVINOS EM GAIOLAS
}

\author{
Lício VELLOSO * \\ Ricardo Peixoto SUMMA ** \\ Mauro PROCKNOR **
}

\begin{abstract}
RFMV-A/10
VELLOSO, L.; SUMMA, R.P.; PROCKNOR, M. Valor nutritivo do pé de milho seco (Zea mays) determinado num ensaio de digistibilidade com bovinos em guiolas. Rev.Fac.Med.vet.Zootec. Univ.S.
\end{abstract} Univ. S. Paulo, 14(1): 79.87, 1977.

RESUMO: Ensaio realizado no C.I.Z.I.P. "Fernando Costa" em Pirassununga (S.P.), tendo sido utilizado três bovinos mestiços Jersey castrados, os quais receberam durante quinze dias alimentação exlusivamente constituída de pé de milho seco (desintegrado). Os cinco primeiros dias foram considerados como de adaptaçâo ao alimento com os animais sendo mantidos em estábulo e nos dez dias subsequentes os bovinos permaneceram em gaiolas de metabolis mo, aproveitando-se os sete últimos dias para controle do alimento e dejeções assim como para a coleta das amostras. Os resultados médios encontrados nas análises bromatológicas foram: Matéria seca (M.S.) 83,30\%; Proteina bruta (P.B.) 7,38\%; Extrato etéreo (E.E.) 2,82\%; Fibra bruta (F.B.) 19,62\% e Extrativos não nitrogenados (E.N.N.) 65,67\% Após o levantamento dos dados da digestibilidade, foram obtidos os seguintes coeficientes de digestibilidade: M.S. 57,20\%; P.B. 27,55\%; E.E. 64,57\%; F.B. 42,38\% e E.N.N. 66,32\%, sendo que os Nutrientes digest iveis totais (N.D.T.) alcançaram 57,99\%.

UNITERMOS: Alimentos, digestibilidade *; Pé de milho seco *; forragens *.

\section{INTRODUÇÃO E LITERATURA}

0 desenvolvimento dos animais está condicionado à qualidade e quantidade dos alimentos ingeridos. Esse desenvolvimento é bastante prejudicado, na Região do Brasil Central, devido à ocorrência de uma estacionalidade climática adversa, causadora de desastrosas consequências para o desfrute do rebanho bovino e consequentemente para a economia nacional.

As causas primordiais do baixo desfrus te nacional, a alta mortalidade, a baixa natalidade e a baixa fertilidade, são originadas principalmente por dois fatores: alimentação e manejo inadequados. Esses fatores ainda impõem um abate demasiadamente tardio (4 e 5 anos), diminuindo ainda mais o desfrute do rebanho bovino nacional. Atualmente, existe a necessidade premente de abreviar-se a idade de abate, tal como ocorre com 08 demais paises produtores, nos quais essa idade encontra-se entre um e dois anos.

No Brasil Central, devido ao clima reinante, os bovinos em regine exclusivo de pastagem, desenvolvem-se somente durante seis meses ao ano, pois estão sujeitos, no período da seca, b forragens escassas e de má qualidade, perdendo peso durante o referido periodo.

\footnotetext{
* Professor Livre-Docente

Departamento de Produção Animal da Faculdade de Medicina Veterinária e Zootecnia da USP.

* * Aluno do 9\% semestre da Faculdade de Medicina Veterinárir e Zootecnia da USP.
} 
Segundo trabalhos de TUNDISI ${ }^{9}$ (1961), esse fato constitue-se no principal fator responsável pelo abate tardio dos bovinos de corte. A evidência desse fato é totalmente percebida quando se observa a curva do desenvolvimento ponderal de bovinos, em regime exclusivo de pastagem, obtida pelo autor, e na qual verifica-se que os animais só estariam prontos para o abate com a idade de três anos no mínimo.

MATíS $^{3}$ (1973) trabalhando com novilhos meio sangue. Guzerá meio sangue Nelore, concluiu que havia equivalência entre silagem de milho e a planta seca desintegrada e que os resultados eram melhores com a adição de um suplemento protéico (farelo de algodão). Verificou ainda o autor, que atraves do uso do suplemento proteico, foi possivel obter-se um peso vivo final aos vinte e sete meses de idade de $471 \mathrm{~kg}$ com a silagem e de $455 \mathrm{~kg}$ com o pé de milho seco triturado. $0 \mathrm{~s}$ ganhos médios diários no período foram: silagem $0,473 \mathrm{~kg}$; pé de milho seco triturado $0,486 \mathrm{~kg}$; silagem mais suplemento proteỉco $0,905 \mathrm{~kg}$ e pé de milho seco triturado mais suplemento protéico 0,838 kg.

Nesse experimento, foi ainda determinada a produção de matéria seca por área, que resultou em $7.215 \mathrm{~kg}$ por hectare para a silagem e em $7.365 \mathrm{~kg}$ por hectare para o pé de milho seco.

CUNHA et alii ${ }^{2}$ (1973) trabalhando com mestiços Santa Gertrudis x Zebu, em confinamento, por um período de 112 dias, utilizando como ração milho (grãos desintegrados) $42 \%$, torta de algodão $15 \%$, feno de leguminosas desintegrado $25 \%$ e palhada de milho desintegrada $18 \%$, obtiveram um ganho de peso diário e conversão alimentar de respectivamente $1,225 \mathrm{~kg} \mathrm{e}]: 8,05$.

MONTAGNINI $^{6}$ (1972) em experimento análogo (mestiços Santa Gertrudęs x Zebu), com duração de 140 dias e utilizando pé de milho integral e seco $60 \%$, feno de mucuna $25 \%$ e torta de algodão $15 \%$, como componentes da raçāo empregada, obteve ganho de peso diário médio de $0,786 \mathrm{~kg}$ e uma conversão alimentar média de 1:11,4 .

Quanto a produção de forragem por unidade de área, esse experimento revelou que a planta integral forneceu $7.000 \mathrm{~kg}$ por hectare, a espiga $4.314 \mathrm{~kg}$ por hectare, o pé sem espiga $2.686 \mathrm{~kg}$ por hectare e a relação de peso entre a espiga e o pé (sem espiga) foi de $1: 1,6$.

VELLOSO $^{10}$ (1970/71) trabalhando com novilhos Nelore, de aproximadamente 20 meses de idade, numa duração experimental de 112 dias, comparou quatro tipos de tratamentos, sendo um deles, constituído de pé de milho integral $80 \%$ e farelo de algodão $20 \%$. A ração assim constituída, forneceu na análise bromatológica os seguintes valores: M.S. 88,06\%; P.B. 10,84\%; E.E. $2,53 \%$; F.B. $26,18 \%$; E.N.N. $56,50 \%$ e Matéria mineral (M.M.) 3,95\%.

0 ganho de peso diário médio observado nos animais submetidos a esse tratamento foi de $0,549 \mathrm{~kg}$ e o consumo diário médio foi de $8,181 \mathrm{~kg}$.

SILVEIRA $^{8}$ (1975) trabalinando com carneiros emasculados e comparando o valor nutritivo da silagem de milho e do pé de milho seco triturado, obteve os seguintes valores para as análises bromatológicas do pé de milho seco triturado: M.S. 88,6\%; P.B. $6,1 \%$; E.E. $1,9 \%$; F.B. $17,3 \%$ e E.N.N. $59,6 \%$. Quanto aos coeficientes de digestibilidade da planta seca triturada o autor obte ve: M.S. 52,6\%; P.B. 50,5\%; E.E. $69,1 \%$; F.B. $56,2 \%$ e E.N.N. 70,1\%.

MELOTTI $^{5}$ (1969) em experimento com carneiros machos castrados, comparou o valor nutritivo da silagem de milho e do "Rolão" de milho (pé de milho integral seco e triturado), obtendo valores para a análise bromatológica e para o coeficiente de digestibilidade do "Rolão" de milho de respectivamente: M.S. $90,17 \%$ e $49,47 \%$; P.B. $7,48 \%$ e $47,51 \%$; E.E. $2,68 \%$ e $76,61 \%$; F.B. $30,42 \%$ e $39,24 \%$ e finalmente E.N.N. $55,17 \%$ e $56,54 \%$.

SILVA et aliii ${ }^{7}$ (1973) promoveram estudos sobre o valor nutritivo, digestibilidade (aparente), balanço de nitrogênio e consumo de silagens de milho e de sorgo, comparando-as com as respectivas plantas secas e desintegradas. Para tanto, utilizaram-se de carneiros machos castrados, atuando pelo processo convencional de coleta total de fezes para a determinaçăo da digestibilidade aparente.

Afirmam os autores, que não foram 
constatadas diferenças significativas e:tre tratamentos quanto aos coeficientes de $\mathrm{dt}$ gestibilidade da M.S., F.B e da Energia bruta (E.B.). $O$ consumo de matéria seca e o balanço de nitrogênio foram significativamente melhores, quando os animais receberam o pé de milho seco desintegrado. Tanto a silagem de sorgo quanto o pé de sorgo seco desintegrado, mostraram-se pobres em proteína bruta, acarretando balanço de nitrogênio negativo nos animais submetidos a esses tratamentos. Houve ligeira tendência dos volumosos secos e desintegrados serem melhor consumidos do que as respectivas silagens que, porém, foram mais digestiveis.

Sendo o milho (Zea mays) um dos suplementos alimentares mais difundidos no Brasil Central e o pé de milho integral (com espiga) moído, uma das formas de se prover alimentação que năo exige tecnologia nem manejo dispendiosos, torna-se necessário a realização de pesquisas a cerca da sua digestibilidade (aparente), visando determinar o seu valor nutritivo como alimento nas épocas secas

\section{MATERIAL E METODOS}

A planta forrageira utilizada no presen. te ensaio foi o pé de milho seco integral (espiga, caule e folhas) desintegrado, proveniente de uma cultura plantada em novembro de 1975 , numa área de 82,28 hectares existente no C.I.Z.I.P. "Fernando Costa" em Pirassurunga (S.P.). Na preparação para o cultivo dessa área, foi feita, inicialmente, a calagem da terra, utilizando-se para tanto de $1.337 \mathrm{~kg}$ por hectare de calcáreo dolomítico. Posteriormente, por ocasião do plantio, foi efetuada a fertilização do solo, com $240 \mathrm{~kg}$ por hectare de superfosfato simples e $65 \mathrm{~kg}$ por hectare de cloreto de potássio. Finalmente, praticou-se a adubaç ${ }^{x}$ " por cobertura" com $139 \mathrm{~kg}$ por hectare de sulfato de amônio. A colheita foi levada a efeito em julho de 1976.
No ensaio de digestibilidade foram utilizados três bovınos mestiços Jersey (castrados). número julgado suficiente por MrDONALD 4 (1973) para trabalhos dessa natureza. Os referidos animais foram previamente submetidos ao consumo de milho, por cinco dias. sendo então levados às gaiolas de metabolismo, onde permaneccram durante dez dias, serido os três primeiros como de adaptação às gaiolas e os sete subseqüentes par efeitu de controle e coleta de amostras.

As gaiolas construídas re madeira, eram providas de comedouro, bandeja culetora de. fezes e funil para coleta de urina.

O fornecimento de água foi efetuado três vezes ao dıa, registrando-se os consumos verificados. Ao milho oferecido diariamente foram acrescentados trinta gramas de suple mento mineral completo.

O milho foi tornecido "ad libitum", isto é, a quantidade colocada à disposição de cada animal, diariamente, foi bastante superior à sua capacidade de ingestão, levandose em consideração os conıumos dos dias anteriores ao período experimsntal.

As amostras das fezes e da urina de cada animal, foram colhidas diariamente durante sete dias sempre pela manhã, precedidas de homogeneização do material. U ma vez identificadas, as amostras foram conservadas em congelador, até o término do período de coleta, quando então aquelas pertencentes ao mesmo animal foram agrupadas, novamente misturadas, e finalmente retiradas as alíquotas que serviram às analises químicas.

Os métodos analíticos seguidos foram aqueles preconizados pela A.O.A.C. ${ }^{1}$ (1955).

\section{RESULTADOS}

Na tabela n' 1, é apresentado o controle do consumo do milho.

Na tabela no 2, encontram-se os dados relativos ao balanço da matéria seca e seu coeficiente de digestibilidade, para cada animal e ainda as médias relativas aos três animais com respectivos desvios. 
TABELA 1 - Controle do consumo do milho

\begin{tabular}{|c|c|c|c|c|c|c|c|c|c|}
\hline $\begin{array}{c}\text { Animal } \\
n ?\end{array}$ & $\begin{array}{c}\text { Pe de } \\
\text { milho } \\
\text { seco } \\
\text { oferecido } \\
(\mathrm{kg})\end{array}$ & $\begin{array}{c}\text { M.S. do } \\
\text { pé de } \\
\text { milho } \\
\text { seco } \\
\text { oferecido } \\
\text { (\%) }\end{array}$ & $\begin{array}{c}M . S . \\
\text { oferecida } \\
\left(k_{g}\right)\end{array}$ & $\begin{array}{l}\text { Sobra } \\
(\mathrm{kg})\end{array}$ & $\begin{array}{c}\text { M.S. da } \\
\text { sobra } \\
\\
(\%)\end{array}$ & $\begin{array}{c}\text { M.S. da } \\
\text { sobra } \\
(\mathrm{kg})\end{array}$ & $\begin{array}{c}\text { Pé de } \\
\text { milho } \\
\text { seco } \\
\text { ingerido } \\
(\mathrm{kg})\end{array}$ & $\begin{array}{c}\text { M.S. do } \\
\text { milho } \\
\text { ingerido } \\
\text { (\%) }\end{array}$ & $\begin{array}{c}\text { M.S. } \\
\text { ingerida } \\
(\mathrm{kg})\end{array}$ \\
\hline 4 & 47,000 & 83,30 & 39,151 & 16,480 & 85,42 & 14077 & 30,101 & 83,30 & 25,074 \\
\hline 5 & 44,000 & 83,30 & 36,652 & 14,810 & 81,54 & 12,076 & 29,503 & 83,30 & 24,576 \\
\hline 6 & 42,000 & 83,30 & 34,986 & 19,990 & 77,80 & 15,552 & 23,330 & 83,30 & 19,434 \\
\hline Média & 44,333 & 83,30 & 36,930 & 17,093 & 81,59 & 13,902 & 27,645 & 83,30 & 23,028 \\
\hline Desvıo & 2,055 & - & 1,712 & 2,159 & 3,11 & 1,425 & 3,061 & - & 2,549 \\
\hline
\end{tabular}

TABELA 2 - Balaņ̣o da matéria seca

\begin{tabular}{|c|c|c|c|c|c|c|c|c|c|}
\hline $\begin{array}{l}\text { Animal } \\
\text { no }\end{array}$ & $\begin{array}{c}\text { Pé de } \\
\text { milho } \\
\text { seco } \\
\text { ingerido } \\
(\mathrm{kg})\end{array}$ & $\begin{array}{c}\text { M.S do } \\
\text { pe de } \\
\text { milho } \\
\text { seco } \\
\text { ingerido } \\
\text { (\%) }\end{array}$ & $\begin{array}{c}\text { M.S. } \\
\text { ingerida } \\
\text { (kg) }\end{array}$ & $\begin{array}{l}\text { Fezes } \\
(\mathrm{kg})\end{array}$ & $\begin{array}{c}\text { M.S. } \\
\text { das } \\
\text { fezes } \\
(\%)\end{array}$ & $\begin{array}{c}\text { M.S. } \\
\text { excretada } \\
\text { nas } \\
\text { fezes } \\
(\mathrm{kg})\end{array}$ & $\begin{array}{c}\text { M.S. } \\
\text { digerida } \\
(\mathrm{kg})\end{array}$ & $\begin{array}{c}\text { Coef. } \\
\text { de } \\
\text { digest. } \\
\text { (\%) }\end{array}$ & $\begin{array}{c}\text { Urina } \\
\text { excretada } \\
\left(\mathrm{kg}_{\mathrm{g}}\right)\end{array}$ \\
\hline 4 & 30,101 & 83,30 & 25,074 & 67,350 & 19,04 & 12,823 & $I 2,25 I$ & 48,86 & 13,470 \\
\hline 5 & 29,503 & 83,30 & 24,576 & 43,440 & 18,95 & 8,232 & 16,344 & 66,50 & 10,930 \\
\hline 6 & 23,330 & 83,30 & 19,434 & 14,950 & 18,92 & 8,505 & 10,929 & 56,24 & 9,450 \\
\hline Média & 27,645 & 83,30 & 23,028 & 51,913 & 18,97 & 9,853 & 13,175 & 57,20 & 11,283 \\
\hline Desvio & $3,0,61$ & - & 2519 & 10,933 & 0,05 & 2,103 & 2,305 & 7,23 & 1,660 \\
\hline
\end{tabular}

Nas tabelas no 3, 4, 5, 6, 7, 8, 9 e 10 são fornecidas as análises bromatológicas, os balanços e os coeficientes de digestibilidade da Proteína bruta, Extrato etéreo, Fibra bruta e Extrativos não nitrogenados, com respectivas médias e desvios. 
TABELA 3 - Análise bromatológica da protetna bruta

\begin{tabular}{c|c|c|c}
\hline $\begin{array}{c}\text { Animal } \\
n !\end{array}$ & $\begin{array}{c}\text { P.B. no pe de } \\
\text { milho seco } \\
(\%)\end{array}$ & $\begin{array}{c}\text { P.B. na } \\
\text { sobra } \\
(\%)\end{array}$ & $\begin{array}{c}\text { P.B. nas } \\
\text { fezes } \\
(\%)\end{array}$ \\
\hline 4 & 7,38 & 8,94 & 10,81 \\
5 & 7,38 & 7,94 & 12,13 \\
6 & 7,38 & 8,19 & 11,56 \\
Média & 7,38 & 8,36 & 11,50 \\
Desvio & - & 0,43 & 0,94 \\
\hline
\end{tabular}

TABELA 4 - Balanço da proteína bruta

\begin{tabular}{c|c|c|c|c}
\hline $\begin{array}{c}\text { Animal } \\
n \%\end{array}$ & $\begin{array}{c}\text { P.B. } \\
\text { ingerida } \\
(g)\end{array}$ & $\begin{array}{c}\text { P.B. } \\
\text { excretada } \\
(\mathrm{g})\end{array}$ & $\begin{array}{c}\text { P.B. } \\
\text { digerida } \\
(\mathrm{g})\end{array}$ & $\begin{array}{c}\text { Coeficiente de } \\
\text { digestibilidade } \\
(\%)\end{array}$ \\
\hline 4 & 1.631 & 1.386 & 245 & 15,02 \\
5 & 1.746 & 999 & 747 & 42,78 \\
6 & 1.308 & 983 & 325 & 24,85 \\
Média & 1.562 & 1.123 & 439 & 27,55 \\
\hline Desvio & 185 & 186 & 220 & 11,49 \\
\hline
\end{tabular}

TABELA 5 - Análise bromatológica do extrato etéreo

\begin{tabular}{c|c|c|c}
\hline $\begin{array}{c}\text { Animal } \\
n !\end{array}$ & $\begin{array}{c}\text { E.E. no pé } \\
\text { de milho seco } \\
(\%)\end{array}$ & $\begin{array}{c}\text { E.E. na } \\
\text { sobra } \\
(\%)\end{array}$ & $\begin{array}{c}\text { E.E. nas } \\
\text { fezes } \\
(\%)\end{array}$ \\
\hline 4 & 2,82 & 3,01 & 2,23 \\
5 & 2,82 & 2,52 & 2,49 \\
6 & 2,82 & 1,96 & 2,90 \\
Média & 2,82 & 2,50 & 2,54 \\
Desvio & - & 0,43 & 0,50 \\
\hline
\end{tabular}

Rev. Fac. Med. vet. Zootec. Univ. S. Paulo, 14(1):79-87, 1977. 
TABELA 6 - Balango do extrato ètéreo

\begin{tabular}{c|c|c|c|c}
\hline $\begin{array}{c}\text { Animal } \\
n o\end{array}$ & $\begin{array}{c}\text { E.E. } \\
\text { ingerido } \\
(g)\end{array}$ & $\begin{array}{c}\text { E.E. } \\
\text { excretado } \\
(g)\end{array}$ & $\begin{array}{c}\text { E.E. } \\
\text { digerido } \\
(g)\end{array}$ & $\begin{array}{c}\text { Coeficiente de } \\
\text { digestibilidade } \\
(\%)\end{array}$ \\
\hline 4 & 681 & 286 & 395 & 58,00 \\
5 & 730 & 205 & 525 & 71,92 \\
6 & 682 & 247 & 435 & 63,78 \\
Média & 698 & 246 & 452 & 64,57 \\
\hline Desvio & 23 & 33 & 54 & 5,71 \\
\hline
\end{tabular}

TABELA 7 - Análise bromatológica da fibra bruta

\begin{tabular}{c|c|c|c}
\hline $\begin{array}{c}\text { Animal } \\
n \%\end{array}$ & $\begin{array}{c}\text { F.B. no pe } \\
\text { de milho seco } \\
(\%)\end{array}$ & $\begin{array}{c}\text { F.B. na } \\
\text { sobra } \\
(\%)\end{array}$ & $\begin{array}{c}\text { F.B. nas } \\
\text { fezes } \\
(\%)\end{array}$ \\
\hline 4 & 19,62 & 20,86 & 24,25 \\
5 & 19,62 & 22,92 & 25,31 \\
6 & 19,62 & 20,59 & 25,91 \\
Média & 19,62 & 21,46 & 25,16 \\
\hline Desvio & - & 1,04 & 0,69 \\
\hline
\end{tabular}

TABELA 8 - Balanço da fibra bruta

\begin{tabular}{c|c|c|c|c}
\hline $\begin{array}{c}\text { Animal } \\
n !\end{array}$ & $\begin{array}{c}\text { F.B. } \\
\text { ingerida } \\
(\mathrm{g})\end{array}$ & $\begin{array}{c}\text { F.B. } \\
\text { excretada } \\
(\mathrm{g})\end{array}$ & $\begin{array}{c}\text { F.B. } \\
\text { digerida } \\
(\mathrm{g})\end{array}$ & $\begin{array}{c}\text { Coeficiente de } \\
\text { digestibilidade } \\
(\%)\end{array}$ \\
\hline 4 & 4.745 & 3.110 & 1.635 & 34,46 \\
5 & 4.423 & 2.084 & 2.339 & 52,88 \\
6 & 3.662 & 2.204 & 1.458 & 39,81 \\
Média & 4.277 & 2.466 & 1.811 & 42,38 \\
Desvio & 454 & 458 & 381 & 7,74 \\
\hline
\end{tabular}


TABELA 9 - Análise bromatológica dos extrativos não nitrogenados

\begin{tabular}{c|c|c|c}
\hline $\begin{array}{c}\text { Animal } \\
n \%\end{array}$ & $\begin{array}{c}\text { E.N.N. no pé } \\
\text { de milho seco } \\
(\%)\end{array}$ & $\begin{array}{c}\text { E.N.N. na } \\
\text { sobra } \\
(\%)\end{array}$ & $\begin{array}{c}\text { E.N.N. nas } \\
\text { fezes } \\
(\%)\end{array}$ \\
\hline 4 & 65,67 & 63,16 & 54,30 \\
5 & 65,67 & 62,91 & 50,34 \\
6 & 65,67 & 65,44 & 51,87 \\
Média & 65,67 & 63,84 & 52,17 \\
Desvio & - & 1,14 & 2,13 \\
\hline
\end{tabular}

TABELA 10 - Balanço dos extrativos não nitrogenados

\begin{tabular}{c|c|c|c|c}
\hline $\begin{array}{c}\text { Animal } \\
n !\end{array}$ & $\begin{array}{c}\text { E.N.N. } \\
\text { ingerido } \\
(g)\end{array}$ & $\begin{array}{c}\text { E.N.N. } \\
\text { excretado } \\
(g)\end{array}$ & $\begin{array}{c}\text { E.N.N. } \\
\text { digerido } \\
(g)\end{array}$ & $\begin{array}{c}\text { Coeficiente de } \\
\text { digestibilidade } \\
(\%)\end{array}$ \\
\hline \multirow{2}{*}{5} & 16.819 & 6.963 & 9.856 & 58,60 \\
5 & 16.472 & 4.144 & 12.328 & 74,84 \\
6 & 12.798 & 4.412 & 8.386 & 65,53 \\
Média & 15.363 & 5.173 & 10.190 & 66,32 \\
Desvio & 1.819 & 1.270 & 1.627 & 6,65 \\
\hline
\end{tabular}

$\mathrm{Na}$ tabela no 11, são apresentados os valores médios dos nutrientes digestíveis do milho. A conversão de unidade (de N.D.T. para $\mathrm{Kcal} / \mathrm{Kg}$ ) foi efetuada segundo a constante preconizada por McDONALD et alii ${ }^{4}$ (1973).

TABELA 11 - Valores médios dos nutrientes digestiveis totais do milho (pé seco)

\begin{tabular}{c|c|c|c|c|c|c}
\hline $\begin{array}{c}\text { M.S.D. } \\
(\%)\end{array}$ & $\begin{array}{c}\text { P.D. } \\
(\%)\end{array}$ & $\begin{array}{c}\text { E.E.D. } \\
(\times 2,25) \\
(\%)\end{array}$ & $\begin{array}{c}\text { F.D. } \\
(\%)\end{array}$ & $\begin{array}{c}\text { E.N.N.D. } \\
(\%)\end{array}$ & $\begin{array}{c}\text { N.D.T. } \\
(\%)\end{array}$ & $\begin{array}{c}\text { E.D. } \\
(\mathrm{Kcal} / \mathrm{kg})\end{array}$ \\
\hline 47,65 & 2,03 & 4,10 & 8,31 & 43,55 & 57,99 & 2.552 \\
\hline
\end{tabular}

Rev. Fac. Med. vet. Zootec. Univ. S. Paulo, 14(1):79-87, 1977. 


\section{DISCUSSÃO}

Os resultados das análises bromatológicas realizadas com o pé de milho seco, neste trabalho, estão bastante próximos daqueles relatados por SILVEIRA ${ }^{8}$ (1975), como se pode notar através dos valores obtidos no presente trabalho e os daquele autor, fornecidos a seguir: M.S. $83,30 \%(88,60 \%)$; P.B. $7,38 \%(6,10 \%)$; E.E. $2,82 \%(1,90 \%) ;$ F.B. $19,62 \%(17,30 \%)$ e E.N.N. $65,67 \%$ $(59,60 \%)$. Com relação aos coeficientes de digestibilidade, apenas o da matéria seca foi ligeiramente superior àquele diwulgado pelo autor citado, ou seja, $57,20 \%(52,60 \%)$, enquanto que, para todos os demais nutrientes, observaram-se coeficientes de digestibilidade mais baixos, conforme são apresentados a seguir: P.B. $27,55 \%(50,50 \%)$; E.E. $64,57 \%$ $(69,10 \%)$; F.B. $42,38 \%(56,20 \%)$ e E.N.N. $66,32 \%(70,10 \%)$.

Efetuando análise bromatológica do "Rolão" de milho, utilizado num experimento de digestibilidade, MELOTTI ${ }^{5}(1969)$ obteve teores superiores para: M.S. $(90,17 \%)$; P.B. $(7,48 \%)$ e F.B. $(30,42 \%)$ e inferiores para E.E. $(2,68 \%)$ e E.N.N. $(55,17 \%)$, em relação aos dados desse experimento, Quanto aos coeficientes de digestibilidade, obteve resultados superiores para P.B. $(47,51 \%)$ e E.E. $(76,61 \%)$ e inferiores para M.S. $(49,47 \%)$; F.B. $(39,24 \%)$ e E.N.N. $(56,54 \%)$.

\section{CONCLUSĀO}

Considerando os dados de ganho em peso de bovinos alimentados com pé de milho seco, em diferentes rações, conforme relatos de VELLOSO ${ }^{10}(1970 / 71)$, MON TAGNINI $^{6}$ (1972), CUNHA et alii ${ }^{2}$ (1973) e $\operatorname{MATTOS}^{3}$ (1973), concluiu-se que os dados da digestibilidade desse volumoso, serão de utilidade para a formulação de rações. Saliente-se, contudo, as diferenças observadas nos coeficientes de digestibilidade entre trabalhos efetuados com ovinos e com bovinos em locais e condiçǒes diversas.

\section{RFMV-A/10}

VELLOSO, L.; SUMMA, R.P.; PROCKNOR, M. Nutritive value of ground corn fodder (Zea mays) as determine through a digestion trial with steers in cages. Rev. Fac. Med. vet. Zootec. Univ. S. Paulo, 14(1): 79.87, 1977

SUMMARY: Three crossbred Jersey steers were used in a digestion trial (in cages), to determine the nutritive value of ground corn fodder (Zea mays). Collection period lasted for seven days (after five days of adaptation to the feed and three days to the cages). Chemical compositon of ground corn fodder was as follows: Dry matter (DM) $83.30 \%$; Crude protein (CP) $7.38 \%$; Ether extract (EE) $2.82 \%$; Crude fiber (CF) 19.62\%; Nitrogen free extract (NFE) $65.67 \%$. Data for coeficients of digestibility were as follows: DM 57.20\%; CP 27.55\%; EE 64.57\%; CF 42.38\%; NFE 66.32\%, being the Total Digestible Nutrients equal to $57.99 \%$

UNITERMS: Food digestibility *; Ground corn fodder *; Forrage *.

\section{REFERENCIAS BIBLIOGRẢFICAS}

1 - A.O.A.C. Official methods of analysis. 8.ed. Washington, 1955. 1008 p.

2 - CUNHA, P.G.; MONTAGNINI, M.I.; ROVERSO, E.A ; SILVA, D.J. Estudo comparado entre grão de sorgo e grão de milho na engorda de bovinos em confinamento. Bol. Ind. anim., S.P., 30(1):1-7, 1973.

3 - MATTOS, J.C.A. Estudo comparativo entre silagem de milho e a planta seca $\mathrm{e}$ desintegrada (hastes, folhas e espigas), na recria e engorda em confinamento de bovinos de corte. Bol. Ind. anim., São Paulo, 30(1):17.49, 1973.

4 - McDONALD, P.; EDWARDS, R.A.; GREENHALGH, J.F.D. Anlmal nutrition, 2.ed. Edinburgh, Oliver \& Boyd, 1973. 479 p.

5 - MELOTTI, L. Determinação do valor nutritivo da silagem e do "Rolão" de mitho, através de ensaio de digestibilidade (aparente) com carneiros. Bol. I nd. a n i m., S ã o P a u lo, 26(único):335-44, 1969. 
6 - MONTAGNINI, M.I.; CUNHA, P.G.; SILVA, D.J.; ROVERSO, E.A. Estudo comparativo entre sorgo e milho integral na engorda de bovinos em confinamento. Bol. Ind. anim., São Paulo, 29(1):15-22, 1972.

7 - SILVA, J.F.C.; GOMIDE, J.A.; FONTES, C.A A. Valor nutritivo das silagens de milho e de sorgo e do pé de milho e pé de sorgo secos. Rev. Ceres, Viçosa, 20(111):347-53, 1973

8 - SILVEIRA, A.C.; VILLARES, J.B.; RAMOS, A.M. Valor nutritivo da silagem de milho e do pé de milho seco e triturado. In: JORNADA CIENTIFICA DA FACULDADE DE CIÊNCIAS MÉDICAS E BIOLÓGICAS DE BO-
TUCATU, 5., Botucatú, 1975. Anals. p.18.

9 - TUNDISI, A.G.A. Alimentação do gado de corte durante o período da seca. SEMINÅRO DE NUTRIÇÃO DE RUMINANTES, São Paulo, 1961. 13f. (Tema 2.5).

10 - VELLOSO, L. Estudo comparativo sobre o valor das silagens de milho e de sorgo do "pé de milho" e de cana desintegrada fornecidas à novilhos Nęlore em regime de confinamento. Bol. Ind. anim., São Paulo, 27/28(úni$\infty): 313-23,1970 / 71$.

Recebido para publicação em 1-3-77 Aprovado para sublicação em 3-8-77 